\title{
Solidification Microstructure, Thermal Properties and Hardness of Magnesium Alloy 20 mass\% Gd Added AZ91D*1
}

\author{
Masaki Sumida*2, Sanghoon Jung and Toshimitsu Okane \\ National Institute of Advanced Industrial Science and Technology (AIST), Digital Manufacturing Research Center, \\ Tsukuba 305-8564, Japan
}

The solidification microstructure, the thermal property, and the hardness were investigated on AZ91D magnesium alloy and on AZ91D magnesium alloy with 20 mass $\%$ gadolinium addition. AZ91D and AZ91D +20 mass $\%$ Gd were solidified by the furnace cooling technique starting from $700^{\circ} \mathrm{C}$ in an Ar flow atmosphere. The microstructure of AZ91D was composed of main $\alpha \mathrm{Mg}$ grains and web-like grain boundary phases of eutectic $\alpha \mathrm{Mg}+\mathrm{Mg}_{17} \mathrm{Al}_{12}$, while that of AZ91D +20 mass $\%$ Gd changes into an $\alpha \mathrm{Mg}$ matrix with dispersed $\mathrm{Al}_{2} \mathrm{Gd}$ particles. SEMEDS analyses showed that the $\mathrm{Al}$ content in an $\alpha \mathrm{Mg}$ matrix of this alloy was very low compared to $\mathrm{AZ} 91 \mathrm{D}$, because $\mathrm{Al}$ is consumed in the $\mathrm{Al}{ }_{2} \mathrm{Gd}$ particles. Differential thermal analysis and quenching experiments were performed in order to clarify this microstructure formation. The thermal conductivity of this alloy, as measured by the laser-flash method, was $129.2 \mathrm{~W} / \mathrm{mK}$ at room temperature. This alloy exhibited a substantial variance from that of AZ91D at $45.1 \mathrm{~W} / \mathrm{mK}$. A higher Vickers hardness $\mathrm{H}_{\mathrm{V}}=96.6$ was yielded compared to AZ91D at $\mathrm{H}_{\mathrm{V}}=63.7$. These properties were well correlated with the results of microstructure and quantitative analysis. [doi:10.2320/matertrans.F-M2009802]

(Received October 21, 2008; Accepted February 3, 2009; Published April 2, 2009)

Keywords: AZ91D, magnesium alloy, gadolinium, microstructure, solidification

\section{Introduction}

AZ91D is a magnesium alloy that is widely used in diecasting and sand-casting processes. Since this alloy shows a good balance of castability and mechanical properties, it is often used for structural components in vehicles, airplanes, mobile computers, digital video recorders, and sports products. Industrial demand for this alloy is increasing rapidly because usage of lightweight materials can reduce the energy consumption of various products. The regulated composition of cast metal AZ91D is $8.5-9.5 \% \mathrm{Al}, 0.45-0.9 \% \mathrm{Zn}$, $<0.05 \% \mathrm{Si}, 0.17-0.4 \% \mathrm{Mn},<0.004 \% \mathrm{Fe},<0.025 \% \mathrm{Cu}$, and $<0.001 \% \mathrm{Ni}$ balanced with $\mathrm{Mg}$ in mass. ${ }^{1)}$ The addition of aluminum strengthens $\mathrm{Mg}$ alloys and enhances the fluidity of the melt, and precipitated $\mathrm{Mg}_{17} \mathrm{Al}_{12}$ at the grain boundary promotes corrosion resistance. ${ }^{2}$ Figure 1(a) shows the MgAl binary phase diagram schematically. ${ }^{3)}$ On the $\mathrm{Mg}$ side, the eutectic reaction, $\mathrm{L}=\alpha \mathrm{Mg}+\mathrm{Mg}_{17} \mathrm{Al}_{12}$, is observed at $437^{\circ} \mathrm{C}$ (Here, $(\mathrm{Mg})$ denotes $\alpha \mathrm{Mg}$.) Figure 1(a) also shows that, with the increase in $\mathrm{Al}$ content to 12.9 mass $\%$, the liquidus temperature of $\alpha \mathrm{Mg}$ decreases and the solidification range increases. Depending on the amount added, this element significantly reduces thermal conductivity. ${ }^{4)}$ The addition of a small amount of zinc also improves the mechanical properties and castability, but the addition of an excessive amount of zinc causes the formation of micro- and macro-cracks during casting. ${ }^{2)}$ In addition, the low boiling point of zinc promotes the formation of pores. A small amount of silicon improves the castability, and precipitated $\mathrm{Mg}_{2} \mathrm{Si}$ at the grain boundary improves the creep resistance characteristics. A small amount of manganese improves corrosion resistance, ${ }^{2)}$ whereas iron, nickel, copper, and chromium are known to degrade corrosion resistance.

\footnotetext{
${ }^{* 1}$ This Paper was Originally Published in Japanese in J. Jpn. Found. Eng. Soc. 80 (2008) 563-570.

${ }^{* 2}$ Corresponding author, E-mail: sumida-m@aist.go.jp
}

(a)

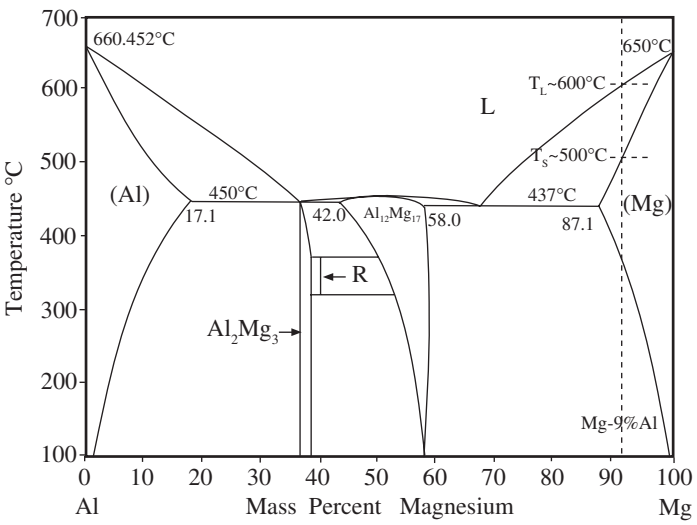

(b)

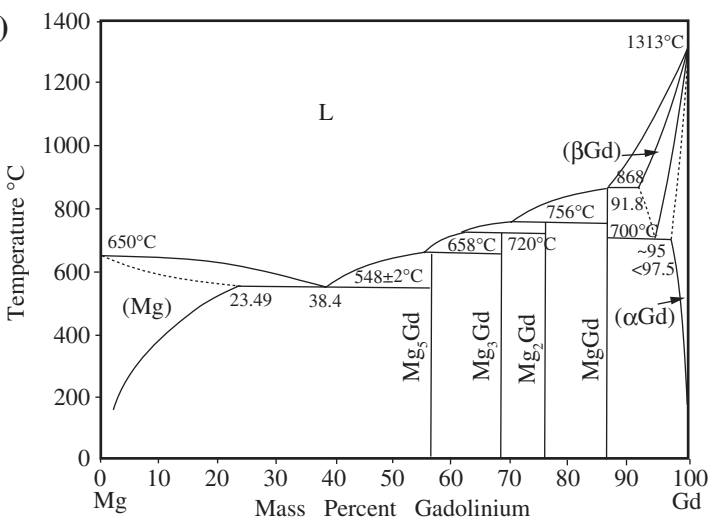

Fig. 1 Schematic phase diagrams of (a) $\mathrm{Mg}-\mathrm{Al}^{3)}$ and (b) $\mathrm{Mg}-\mathrm{Gd}$ binary system. ${ }^{9)} T_{\mathrm{L}}$ and $T_{\mathrm{S}}$ of $\mathrm{Mg}-9$ mass $\% \mathrm{Al}$ are shown in (a).

The solidification microstructure of AZ91D alloy has been widely reported ${ }^{5,6)}$ and is composed of primary $\alpha \mathrm{Mg}$ grains and web-like grain boundaries, where eutectic $\alpha \mathrm{Mg}+$ $\mathrm{Mg}_{17} \mathrm{Al}_{12}$ is residual. Trace elements of zinc and other impurities are not found and do not form the third phase in the microstructure, indicating that these impurities are dissolved 
in grains. The liquidus and solidus temperatures of AZ91D are $T_{\mathrm{L}}=598^{\circ} \mathrm{C}$ and $T_{\mathrm{S}}=470^{\circ} \mathrm{C}$, respectively, and, between these temperatures, primary and main $\alpha \mathrm{Mg}$ grains begin to nucleate and grow. The final solidification occurs at $420^{\circ} \mathrm{C}$, as the eutectic reaction takes place at the grain boundary. Figure 1(a) indicates that the $T_{\mathrm{L}}$ and $T_{\mathrm{S}}$ of $\mathrm{Mg}-9$ mass $\% \mathrm{Al}$ binary alloy are approximately $600^{\circ} \mathrm{C}$ and $500^{\circ} \mathrm{C}$, respectively. Thus, small amounts of impurities in AZ91D reduce $T_{\mathrm{L}}$ and $T_{\mathrm{S}}$ by a few degrees Celsius and approximately $30^{\circ} \mathrm{C}$, respectively. Grain size generally depends on the cooling rate. This results in the die-cast microstructure being much finer than that obtained under sand-casting, even though the microstructures are composed of the same phases. Advantages of AZ91D over other Mg-based alloys include the fact that it contains a large amount of $\mathrm{Al}$, and both $T_{\mathrm{L}}$ and the casting temperature are low, which is advantageous for extending the life of mold dies. However, its disadvantages include low thermal and electrical conductivities, low ductility, and low impact resistance.

Alloying is a conventional but effective technique used to improve microstructure and material properties. The addition of secondary elements yields the effects of solid-solutioning, grain refinement, precipitation, and grain boundary control for metallic materials. The addition of rare-earth (RE) elements to $\mathrm{Mg}$ alloys increases mechanical strength ${ }^{7)}$ and fluidity, ${ }^{8)}$ and also enhances thermal stability and corrosion resistance by the precipitation of hard and thermally stable intermetallics. Figure 1(b) shows the $\mathrm{Mg}-\mathrm{Gd}$ binary phase diagram, where eutectic reaction, $\mathrm{L}=\mathrm{Mg}+\mathrm{Mg}_{5} \mathrm{Gd}$, is found at $548^{\circ} \mathrm{C}$ on the $\mathrm{Mg}$ side. ${ }^{9}{ }^{\prime}$ The maximum solid solubility of $23.5 \mathrm{mass} \% \mathrm{Gd}(4.5 \mathrm{~mol} \%)$ is found at $548^{\circ} \mathrm{C}$, and because the solubility is sufficiently large compared to the maximum solubility of $\mathrm{Al}$ of 12.9 mass\% (Fig. 1(a)), it is expected that Gd-added $\mathrm{Mg}$ alloys will enhance the mechanical properties by solid-solutioning. Moreover, since the Gd solubility limit in $\alpha \mathrm{Mg}$ decreases from 23.5 mass $\%$ $\mathrm{Gd}$ at the eutectic temperature to 3.8 mass $\% \mathrm{Gd}$ at $200^{\circ} \mathrm{C}$ and since the gradient of the solvus line of $\alpha \mathrm{Mg} / \alpha \mathrm{Mg}+\mathrm{Mg}_{5} \mathrm{Gd}$ is quite small, precipitation control by subsequent ageing treatment is effective and can improve hardness. ${ }^{10-14)}$

Since the solidification behavior of AZ91D is similar to that of Mg-9 mass\% Al, the Mg-Al-Gd ternary phase diagram can be used to predict the solidification behavior of Gd-added AZ91D alloy. Figure 2(a) shows the liquidus surface of the $\mathrm{Mg}$-Al-Gd ternary equilibrium phase diagram, ${ }^{15,16)}$ showing that the primary phase field of $\alpha \mathrm{Mg}$ is located near the $\mathrm{Mg}$ corner. The primary phase field of $\mathrm{Al}_{2} \mathrm{Gd}$ is broad and is extended to that of $\alpha \mathrm{Mg}$. $\mathrm{Al}_{2} \mathrm{Gd}$ is a line compound with a cubic structure of $\mathrm{MgCu}_{2}$-type and a congruent melting temperature of $1525^{\circ} \mathrm{C} .{ }^{17,18)}$ Assuming that $\mathrm{Gd}$ is added to $\mathrm{Mg}-9$ mass\% Al alloy, the composition of (Mg-9 mass\% $\mathrm{Al})+x$ mass $\% \mathrm{Gd}$ is then located along the broken line in Fig. 2(a). The primary phase is $\alpha \mathrm{Mg}$ when $x$ is below approximately 2 , but changes to $\mathrm{Al}_{2} \mathrm{Gd}$ as $x$ increases. Figure 2(b) shows an isothermal section at $400^{\circ} \mathrm{C}$ of this ternary diagram. ${ }^{19)}$ In the vicinity of the $\mathrm{Mg}$ corner, there is region of $\alpha \mathrm{Mg}$ solid solution, and regions of $\alpha \mathrm{Mg}+$ $\mathrm{Mg}_{17} \mathrm{Al}_{12}, \quad \alpha \mathrm{Mg}+\mathrm{Mg}_{17} \mathrm{Al}_{12}+\mathrm{Al}_{2} \mathrm{Gd}, \quad \alpha \mathrm{Mg}+\mathrm{Al}_{2} \mathrm{Gd}$, $\alpha \mathrm{Mg}+\mathrm{Al}_{2} \mathrm{Gd}+\mathrm{Mg}_{5} \mathrm{Gd}$, and $\alpha \mathrm{Mg}+\mathrm{Mg}_{5} \mathrm{Gd}$ are connected to the region of $\alpha \mathrm{Mg}$ solid solution. The composition

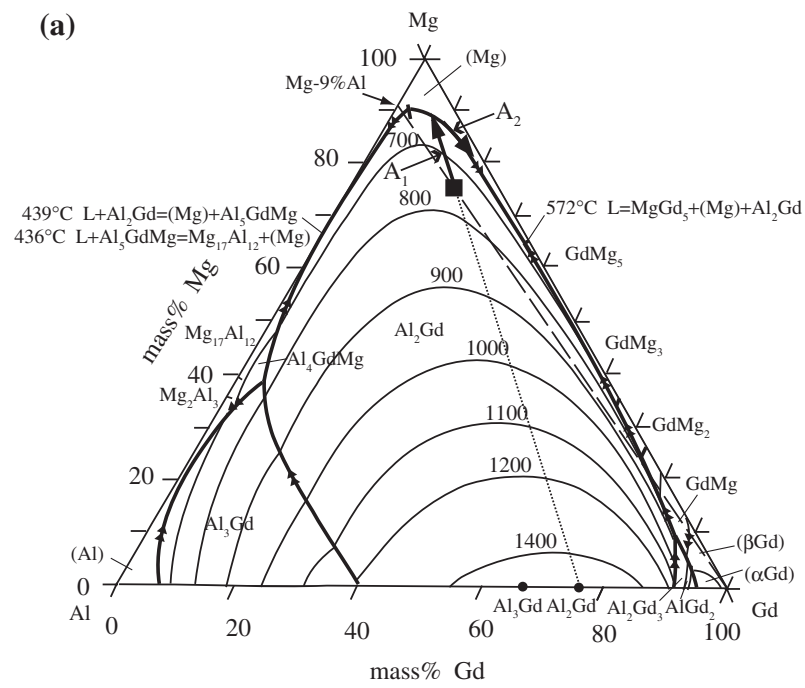

(b)

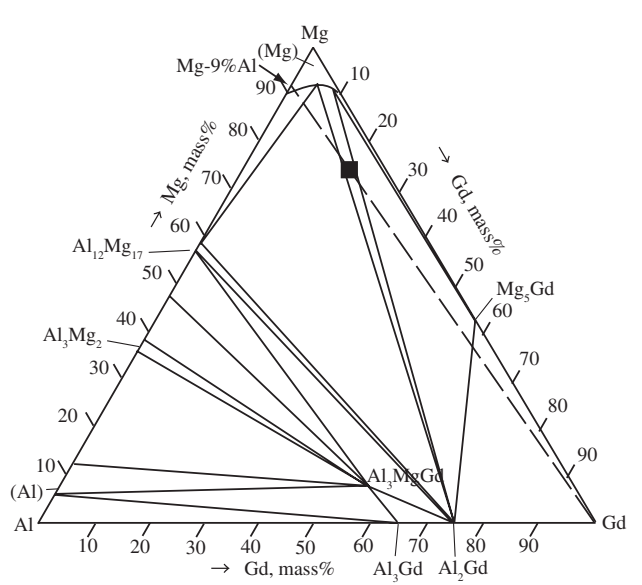

Fig. 2 Schematic phase diagrams of (a) the liquidus surface ${ }^{15}$ ) and (b) the isothermal section at $400^{\circ} \mathrm{C}^{19)}$ of $\mathrm{Mg}$-Al-Gd ternary system. The solid square indicates $(\mathrm{Mg}-9$ mass $\% \mathrm{Al})+20$ mass $\% \mathrm{Gd}$.

around (Mg-9 mass\% $\mathrm{Al})+20$ mass $\% \mathrm{Gd}$, denoted by a solid square in this figure, is located inside the $\alpha \mathrm{Mg}+\mathrm{Al}_{2} \mathrm{Gd}$ two-phase region, where microstructure with no third phase may be obtained. Assuming equilibrium solidification of $(\mathrm{Mg}-9$ mass\% $\mathrm{Al})+20$ mass\% Gd, the arrows $\mathrm{A}_{1}$ and $\mathrm{A}_{2}$ in Fig. 2(a) shows its solidification route. $A_{1}$ is directed along the extrapolation of the dotted line between (Mg-9 mass\% $\mathrm{Al})+20$ mass $\% \mathrm{Gd}$ and $\mathrm{Al}_{2} \mathrm{Gd}$, and represents the primary $\mathrm{Al}_{2} \mathrm{Gd}$ crystallization. $\mathrm{A}_{2}$ corresponds to eutectic solidification of $\alpha \mathrm{Mg}+\mathrm{Al}_{2} \mathrm{Gd}$. Since $\mathrm{A}_{2}$ locates near the $\mathrm{Mg}-\mathrm{Gd}$ binary side, Gd partitions principally into the solidified $\alpha \mathrm{Mg}$, but $\mathrm{Al}$ does not. Consequently, the solidified alloy is expected to improve the thermal conductivity. Recalling that the solidification occurs on the $\mathrm{Mg}-\mathrm{Al}$ side in $\mathrm{Mg}-9$ mass\% $\mathrm{Al}$ alloy, a completely different solidification route and microstructure can be obtained by the addition of a large amount of $\mathrm{Gd}$.

Based on these considerations, it is thought that the mechanical and thermal properties of AZ91D can be improved by the addition of 20 mass $\% \mathrm{Gd}$, while fluidity is not degraded because its melt contains a large amount of fluidity effective $\mathrm{Al}$ and $\mathrm{Gd}$, an RE element. The objective of the present study is to examine the solidification micro- 
structure of AZ91D + 20 mass\% Gd alloy $(\mathrm{Mg}-7.9 \mathrm{~mol} \%$ $\mathrm{Al}-3.8 \mathrm{~mol} \% \mathrm{Gd}-0.3 \mathrm{~mol} \% \mathrm{Zn}$ ) and to clarify its formation behavior during solidification. The thermal properties and hardness of the obtained solidification microstructure were also investigated, along with those of AZ91D solidified under the same conditions.

\section{Experimental}

Alloyed samples were prepared by the conventional solidification technique. The nominal composition of the samples is AZ91D + 20 mass\% Gd and AZ91D. The melt was created in the desired composition by mixing the appropriate amount of 1-5 mm AZ91D chips and Gd blocks that were $10 \mathrm{~mm}$ in size. Approximately $30 \mathrm{~g}$ of this mixture was placed into an alumina (SSA-S) crucible with an inner diameter of $16 \mathrm{~mm}$ and a height of $150 \mathrm{~mm}$ and then heated to melting in an Ar gas atmosphere within a box-type vacuum furnace (SMA-20S, Shimadzu Co., internal volume of $460 \times 500 \times 435 \mathrm{~mm}^{3}$ ). Evacuation by rotary pump and Ar gas introduction was performed three times before heating to ensure gas replacement, after which Ar flow was maintained at $1 \mathrm{~L} / \mathrm{min}$ during heating and cooling. The mixture was held at a temperature of $700^{\circ} \mathrm{C}$ for $1 \mathrm{~h}$ and then furnace-cooled to room temperature, which took 3-5 hours. Rod-shaped samples of $\phi 16 \mathrm{~mm} \times 80 \mathrm{~mm}$ were formed by mechanical breakage of the alumina crucible.

Small pieces cut from the rods were polished, and microstructure observation was performed by optical microscopy and EDS quantitative analysis was done by scanning electron microscopy with energy dispersive spectroscopy (SEM-EDS, JEOL JSM-7400F, acceleration voltage of $15 \mathrm{kV}$ ). Lines of $\mathrm{Mg} \mathrm{K} \alpha, \mathrm{Al} \mathrm{K} \alpha, \mathrm{Zn} \mathrm{K} \alpha$, and $\mathrm{Gd} \mathrm{L} \alpha$ were taken, where ZAF calibration was performed automatically for EDS quantitative analyses. Phase identification was performed by X-ray diffraction analysis with a $\mathrm{Cu}$ target (XRD, JDX-3530, JEOL). The measurements were performed by the $\theta / 2 \theta$ method, and detected phases were identified by the JCPDS database.

Differential thermal analysis (DTA, Shimadzu DTG-60H) was performed in order to determine the melting, crystallization, and eutectic temperatures of each alloy. Using alumina crucibles, $30-40 \mathrm{mg}$ of each sample was supplied. The heating and cooling rates of AZ91D were $5^{\circ} \mathrm{C} / \mathrm{min}$ in the range of $300-700^{\circ} \mathrm{C}$ in flowing $\mathrm{Ar}$ at $200 \mathrm{cc} / \mathrm{min}$. Since the reaction temperature of AZ91D + 20 mass $\%$ Gd was high compared to AZ91D and liquid evaporation was problematic in preliminary studies, heating and cooling rates of $20^{\circ} \mathrm{C} / \mathrm{min}$ and a range of $300-800^{\circ} \mathrm{C}$ were chosen for this alloy. The melting temperature $\left(T_{\mathrm{L}}\right)$ was determined at the cross-points of extrapolated tangents of the end of the endothermic peak in heating curves. The crystallization temperature $\left(T_{\mathrm{cr}}\right)$ was determined from the cooling curve defined at the cross-points of extrapolated tangents of the first exothermic peak. Generally, the reaction temperature of DTA depends on the heating and cooling rates, and the lower rate can detect a value closer to the equilibrium reaction temperature. In preliminary studies on AZ91D, $T_{\mathrm{L}}=599^{\circ} \mathrm{C}$ and $T_{\mathrm{cr}}=581^{\circ} \mathrm{C}$ were obtained upon heating and cooling at $5^{\circ} \mathrm{C} / \mathrm{min} . T_{\mathrm{L}}=$ $612^{\circ} \mathrm{C}$ and $T_{\mathrm{cr}}=587^{\circ} \mathrm{C}$ were obtained upon heating and cooling at $20^{\circ} \mathrm{C} / \mathrm{min}$. These results revealed that $T_{\mathrm{L}}$ had good correspondence with the value $\left(598^{\circ} \mathrm{C}\right)$ reported in the literature ${ }^{2)}$ at $5^{\circ} \mathrm{C} / \mathrm{min}$, and differences of $13^{\circ} \mathrm{C}$ in $T_{\mathrm{L}}$ and $6^{\circ} \mathrm{C}$ in $T_{\text {cr }}$ at $20^{\circ} \mathrm{C} / \mathrm{min}$ were observed. However, for the abovementioned reasons, the values obtained at heating and cooling rates of $20^{\circ} \mathrm{C} / \mathrm{min}$ were taken as the reaction temperatures for AZ91D + 20 mass $\%$ Gd. Thus, for AZ91D + 20 mass $\% \mathrm{Gd}$, as in the preliminary measurements, it is necessary to take into account the difference due to the heating and cooling rates.

Water-quenching experiments were conducted in order to investigate the solidification behavior of the alloy samples. Samples were prepared from alloy blocks of $0.2 \mathrm{~g}$ to $0.9 \mathrm{~g}$ in mass. These were heated to $700^{\circ} \mathrm{C}$ and maintained at that temperature for $15 \mathrm{~min}$. Then, each block was cooled at $5^{\circ} \mathrm{C} /$ $\min$ in the same furnace. This cooling rate was chosen because it is similar to that used for the sand-casting of $\mathrm{Mg}$ alloys. In order to preserve the solidified morphology, the alloy blocks were quenched during cooling by dropping them into a water bath. Since the difference in the exothermic peak temperatures of the DTA cooling curve due to different cooling rates was relatively small in the preliminary experiments, the water-quench temperature $\left(T_{\mathrm{WQ}}\right)$ was selected based on four conditions above and below these temperatures. These samples were also subjected to microstructure observation.

Thermal properties were measured by the laser flash method $^{20)}$ (TC-7000, Ulvac Co.). The thermal diffusivity $(\alpha)$ and specific heat capacity $\left(C_{\mathrm{p}}\right)$ of disk-shaped samples $10 \mathrm{~mm}$ in diameter and $1 \mathrm{~mm}$ in thickness were analyzed at room temperature. The half time method was used for the thermal diffusivity measurements, and sapphire was used as the standard sample for the absorbed heat measurement, where glassy carbon was attached as the light recipient plate. The density $(\rho)$ of the samples was measured from their volumes and weights. No calibration was conducted for the volume fraction or the weight of pores in samples. The thermal conductivity $(\kappa)$ was calculated using the following equation: $\kappa=\rho \times C_{\mathrm{p}} \times \alpha$, where the mean values of three measurements were obtained. Micro-Vickers hardness was measured (Akashi HV-114) on the polished surfaces of the samples. The mean values of 20 measurements were obtained under the condition of a $0.1 \mathrm{kgf}$ load with a duration of $15 \mathrm{sec}$.

\section{Results and Discussion}

Figure 3 shows the optical microstructure of samples (a) AZ91D + 20 mass \% Gd and (b) AZ91D. In Fig. 3(a), $\alpha \mathrm{Mg}$ is the matrix phase, and globular $\mathrm{Al}_{2} \mathrm{Gd}$ particles are dispersed within it. These particles were $10 \mu \mathrm{m}$ in size and were approximately uniformly distributed. No grain boundary phase was observed. In Fig. 3(b), a typical microstructure of AZ91D was observed. $\alpha \mathrm{Mg}$ grains are surrounded by a web-like grain boundary of $\alpha \mathrm{Mg}+\mathrm{Mg}_{17} \mathrm{Al}_{12}$ eutectic. These figures showed a drastic change in the solidification microstructure of AZ91D by the addition of 20 mass $\%$ Gd. Figure 4 shows XRD patterns of AZ91D + 20 mass\% Gd and AZ91D. In Fig. 4(a) of the AZ91D + 20 mass $\% \mathrm{Gd}$ alloy, diffraction patterns of $\alpha \mathrm{Mg}$ and $\mathrm{Al}_{2} \mathrm{Gd}$ 

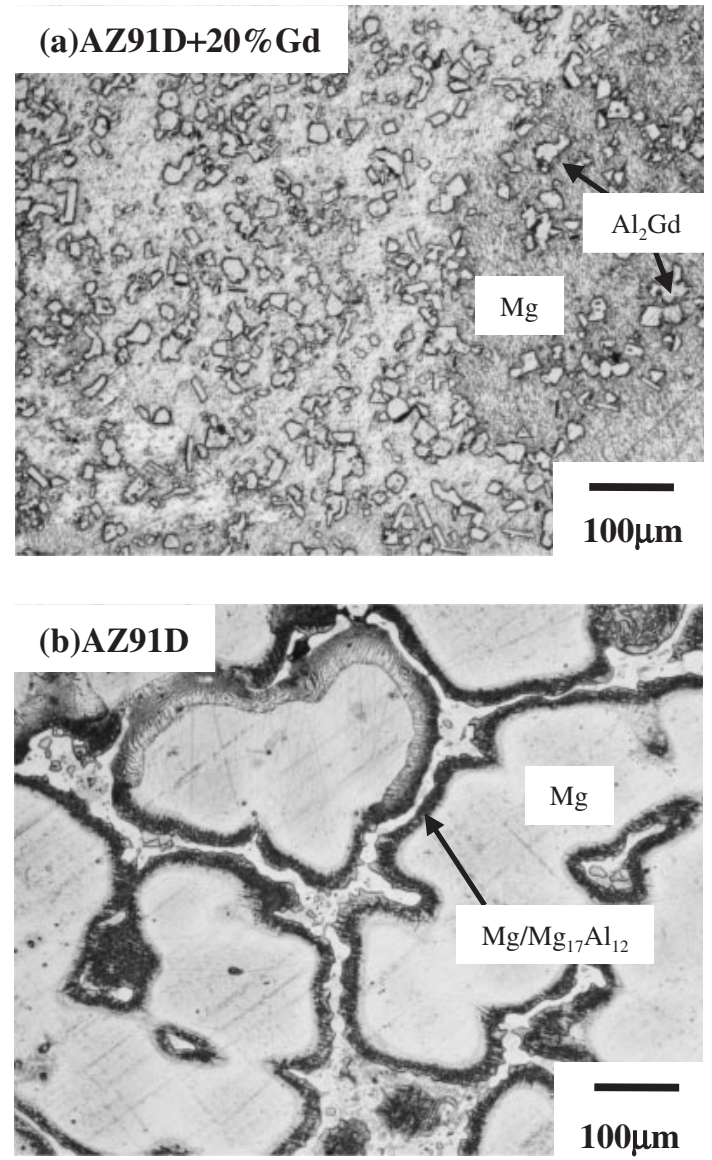

Fig. 3 Optical photomicrographs of solidification microstructure of (a) AZ91D + 20 mass\% Gd and (b) AZ91D.
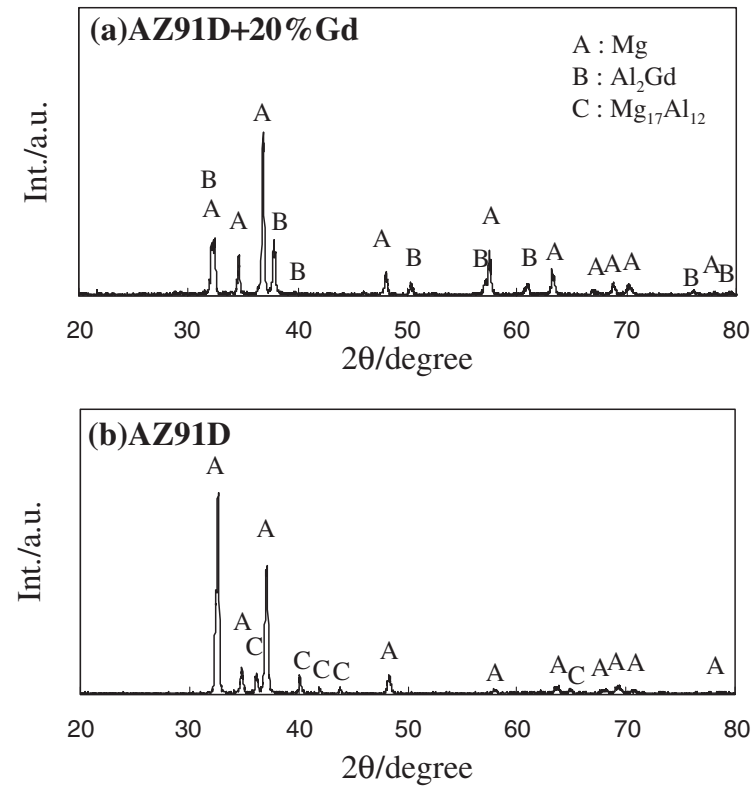

Fig. 4 XRD patterns of (a) AZ91D + 20 mass\% Gd and (b) AZ91D.

were detected. In Fig. 4(b), $\alpha \mathrm{Mg}$ and $\mathrm{Mg}_{17} \mathrm{Al}_{12}$ phases of the AZ91D alloy were detected, revealing good correspondence to the differences in the microstructure.

Figure 5(a) shows an SEM composition image of AZ91D + 20 mass $\%$ Gd, and the concentration distributions
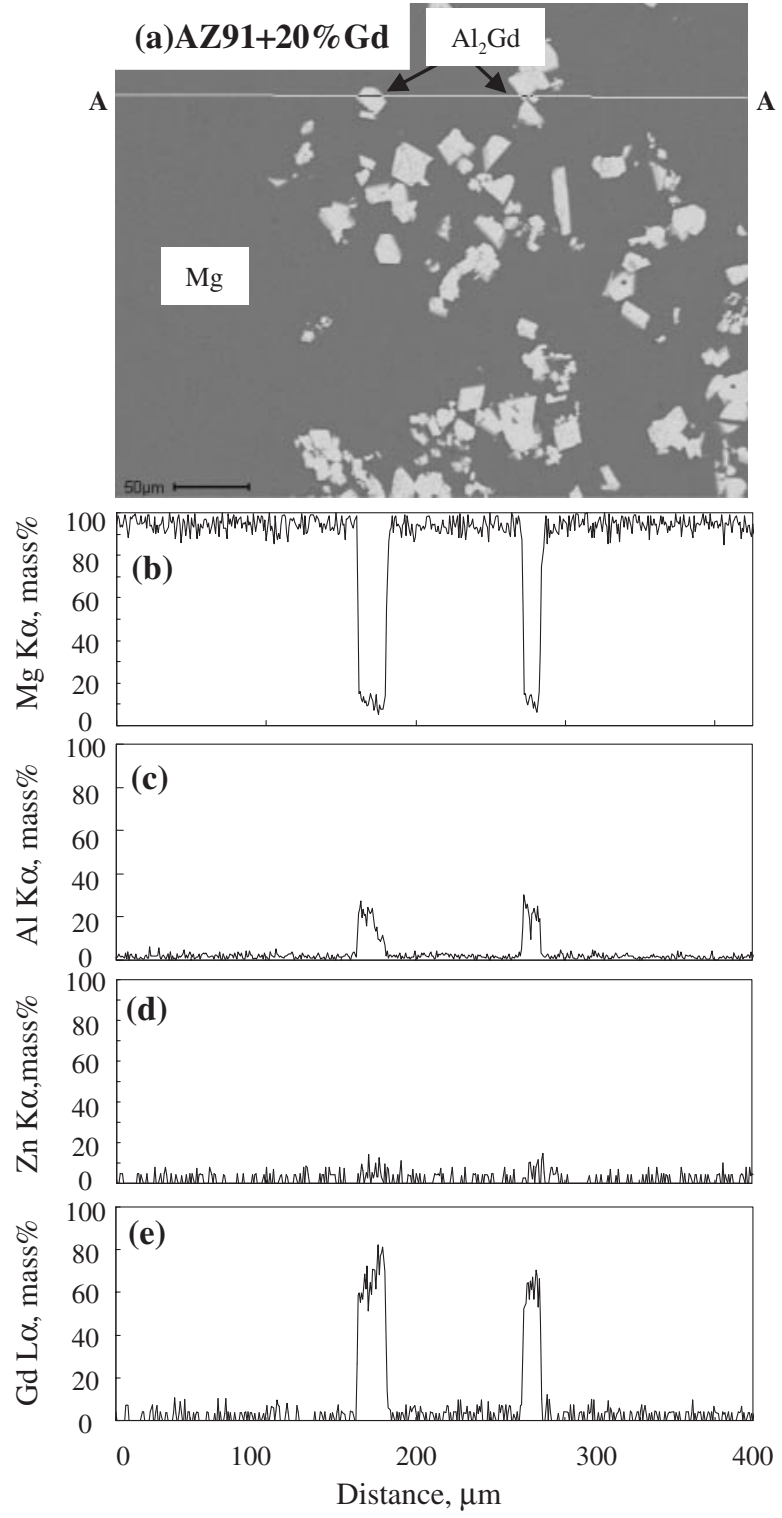

Fig. 5 (a) SEM compositional image of AZ91D + 20 mass $\% \mathrm{Gd}$, and results of EDS line analysis of (b) $\mathrm{Mg}$, (c) Al, (d) $\mathrm{Zn}$, and (e) Gd along horizontal line AA.

by the EDS line analyses along horizontal line AA are shown for (b) $\mathrm{Mg}$, (c) Al, (d) Zn, and (e) Gd. Figure 6(a) shows the SEM composition image of AZ91D, and the concentration distributions along horizontal line BB are shown for (b) Mg, (c) Al, and (d) Zn. In Fig. 5(a), the matrix is shown in gray, and blocky particles are shown in white. These correspond to $\alpha \mathrm{Mg}$ and $\mathrm{Al}_{2} \mathrm{Gd}$, respectively. In Fig. 6(a), AZ91D contains $\alpha \mathrm{Mg}$ grains, shown in gray, along with $\mathrm{Mg}_{17} \mathrm{Al}_{12}$, shown in white. From Figs. 5(b) through $5(\mathrm{e})$, each element had a flat distribution in the $\alpha \mathrm{Mg}$ matrix, but $\mathrm{Mg}$ was depressed and $\mathrm{Al}$ and $\mathrm{Gd}$ were concentrated at particles. The compositions of these regions were approximately consistent with that of $\mathrm{Al}_{2} \mathrm{Gd}(\mathrm{Al}: \mathrm{Gd}=25.5: 74.5$ in mass\%). The figures also show that most of the $\mathrm{Al}$ and $\mathrm{Gd}$ concentrated in the $\mathrm{Al}_{2} \mathrm{Gd}$ and not distributed in the $\alpha \mathrm{Mg}$ matrix. Figures 6(b) through 6(e) show that $\mathrm{Mg}$ was reduced and $\mathrm{Al}$ was concentrated at the grain boundary, but 5-10\% of the $\mathrm{Al}$ was distributed in $\alpha \mathrm{Mg}$ grains. The $\mathrm{Al}$ concen- 


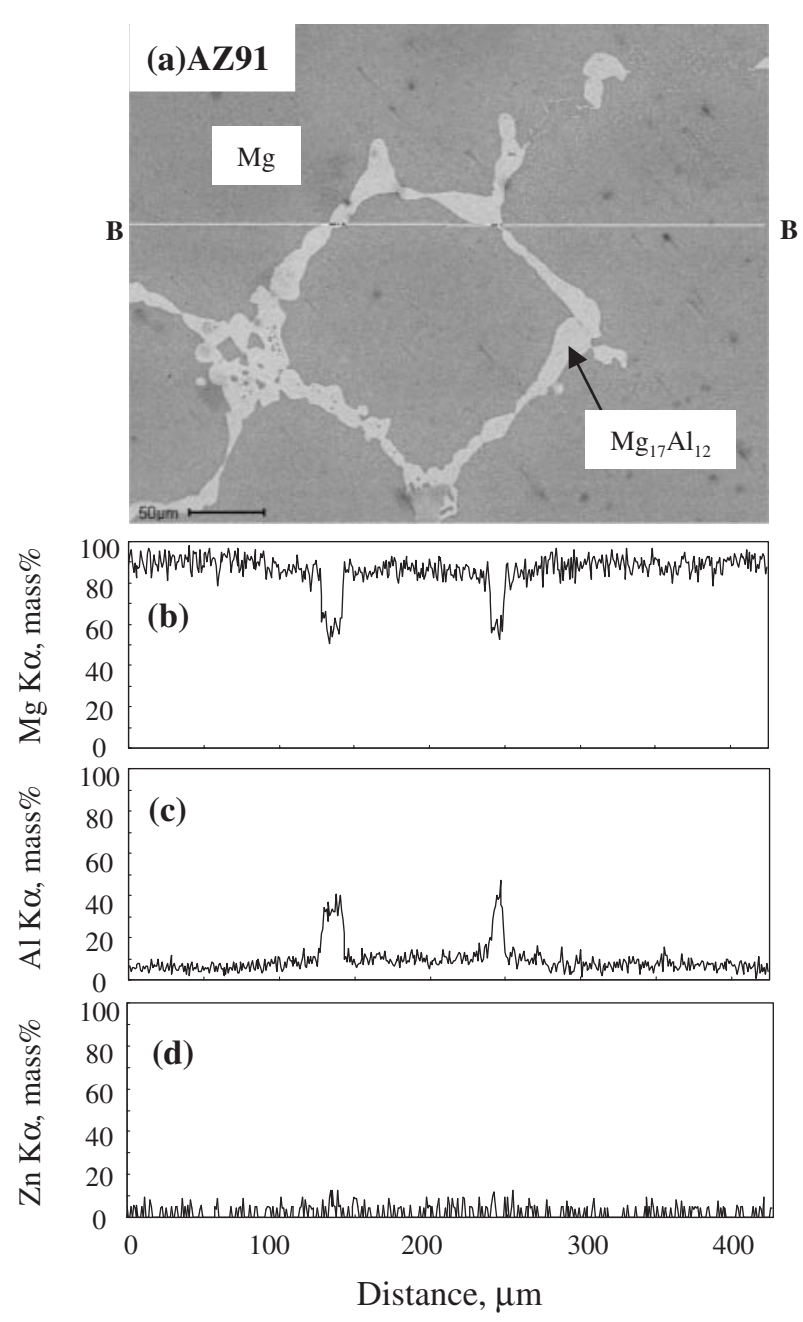

Fig. 6 (a) SEM compositional image of AZ91D, and results of EDS line analysis along horizontal line $\mathrm{BB}$, (b) $\mathrm{Mg}$, (c) $\mathrm{Al}$, and (d) $\mathrm{Zn}$.

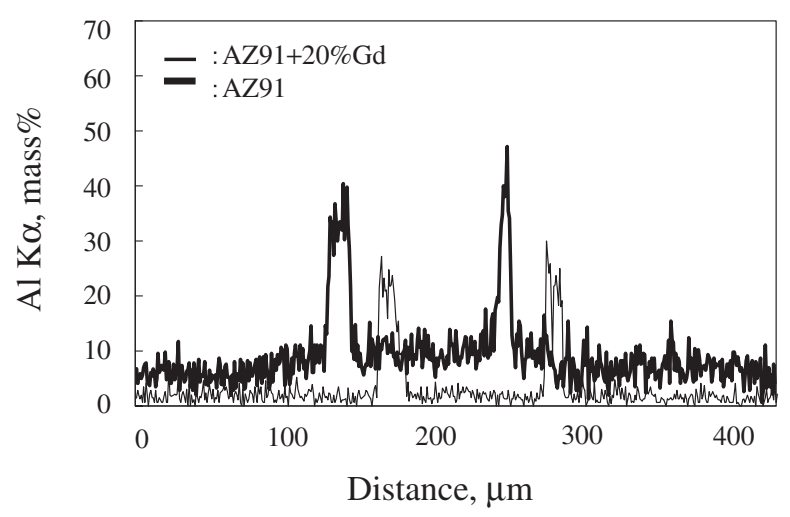

Fig. 7 Al concentration distribution along horizontal lines AA in Fig. 5(a) and BB in Fig. 6(a).

tration distribution of AZ91D + 20 mass $\%$ Gd shown in Fig. 5(c) and that of AZ91D shown in Fig. 6(c) are presented together in Fig. 7, which shows that the Al concentration in $\alpha \mathrm{Mg}$ grains largely decreased in AZ91D + 20 mass\% Gd, as compared to AZ91D. This occurs because the solidification route has progressed along arrows $\mathrm{A}_{1}$ and $A_{2}$ in Fig. 2(a).
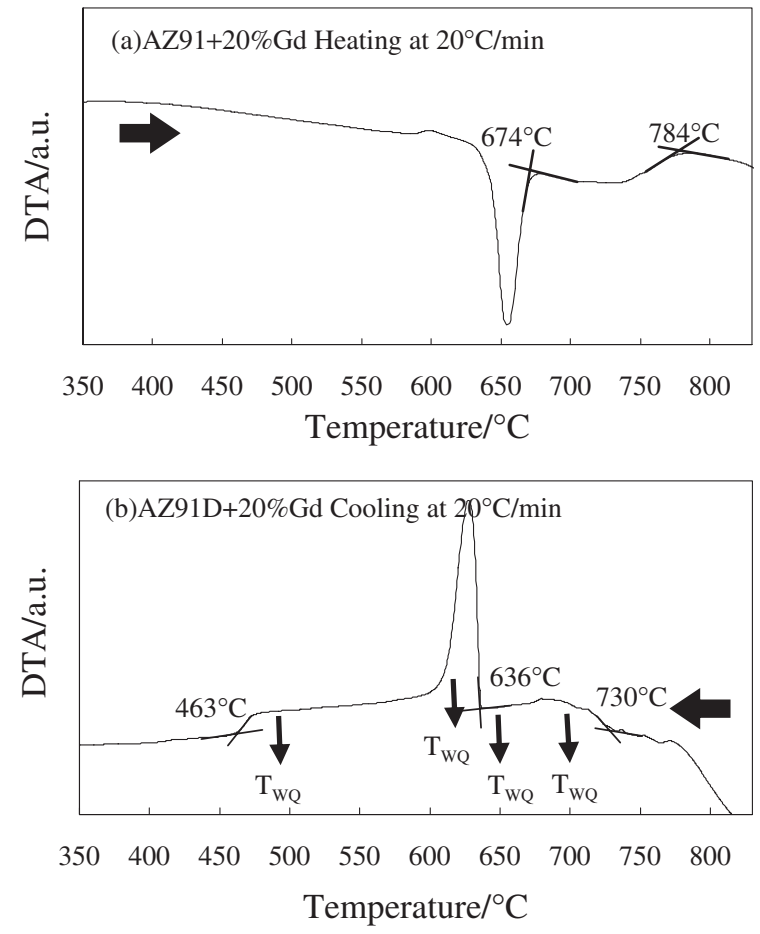

Fig. 8 (a) DTA heating and (b) cooling curves of AZ91D +20 mass $\%$ Gd. The downward arrows indicate the water-quench temperature $\left(T_{\mathrm{WQ}}\right)$ in Fig. 10.
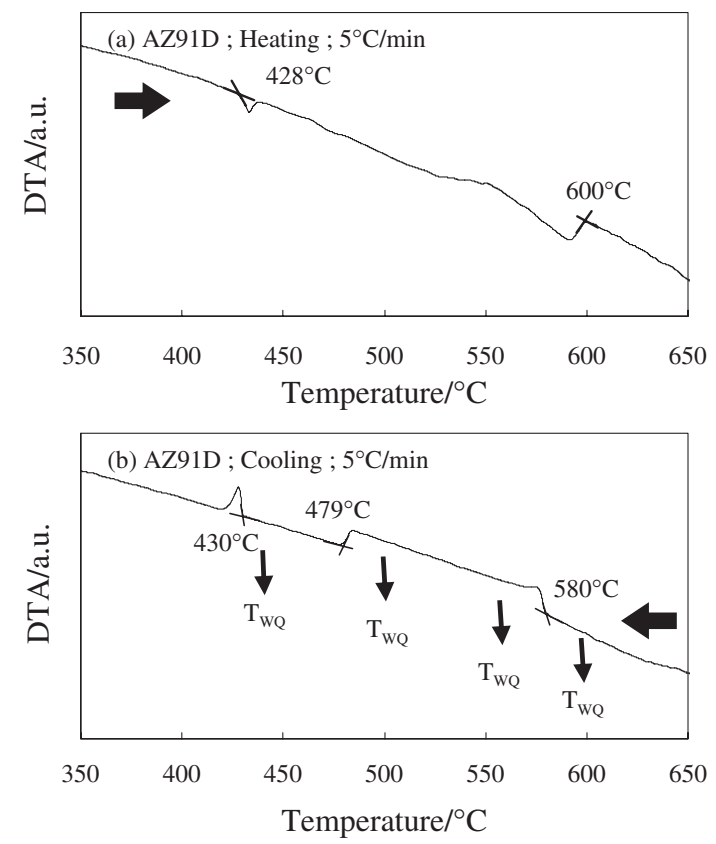

Fig. 9 (a) DTA heating and (b) cooling curves of AZ91D. The downward arrows indicate the water-quench temperature $\left(T_{\mathrm{WQ}}\right)$ in Fig. 11.

Figures 8 and 9 show the DTA heating and cooling curves of AZ91D + 20 mass \% Gd and AZ91D, respectively. Figure 8(a) shows that the endothermic peak started at $\sim 590^{\circ} \mathrm{C}$ and ended at $674^{\circ} \mathrm{C}$ upon heating. Since the melt started to oxidize almost simultaneously upon its formation, heat release occurred and the DTA curve moved upwards slightly at $\sim 590^{\circ} \mathrm{C}$. This leads to difficulty in drawing 


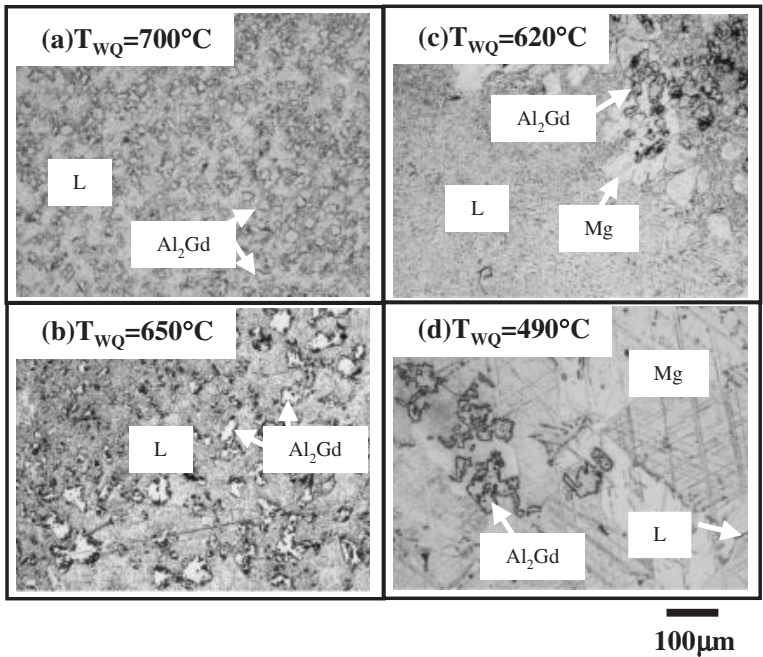

Fig. 10 Quenching temperature dependence of the optical photomicrographs of microstructure of AZ91D + 20 mass $\%$ Gd. Water quenching was performed during cooling at $5^{\circ} \mathrm{C} / \mathrm{min}$ from $700^{\circ} \mathrm{C}$, at (a) $T_{\mathrm{WQ}}=$ $700^{\circ} \mathrm{C}$, (b) $T_{\mathrm{WQ}}=650^{\circ} \mathrm{C}$, (c) $T_{\mathrm{WQ}}=620^{\circ} \mathrm{C}$, and (d) $T_{\mathrm{WQ}}=490^{\circ} \mathrm{C}$.

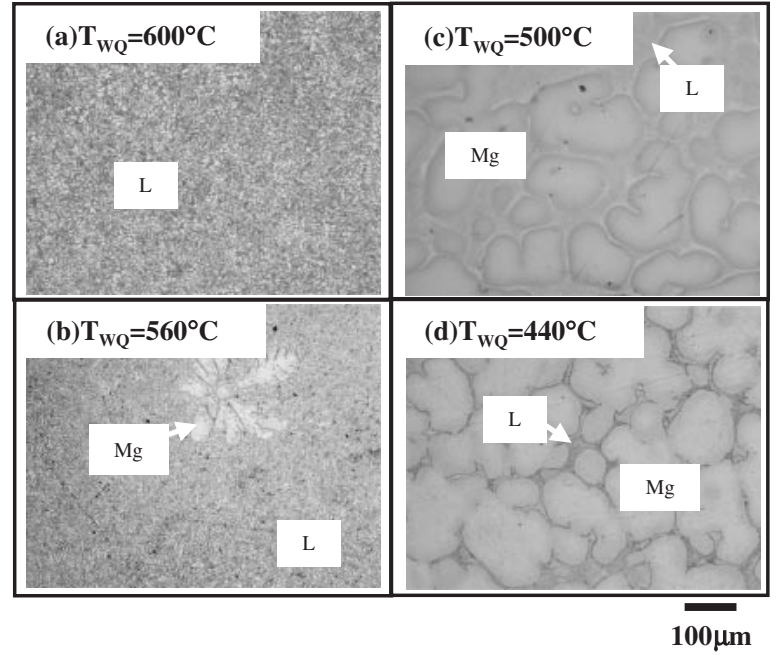

Fig. 11 Quenching temperature dependence of the optical photomicrographs of microstructure of AZ91D. Water quenching was performed during cooling at $5^{\circ} \mathrm{C} / \mathrm{min}$ from $700^{\circ} \mathrm{C}$, at (a) $T_{\mathrm{WQ}}=600^{\circ} \mathrm{C}$, (b) $T_{\mathrm{WQ}}=$ $560^{\circ} \mathrm{C}$, (c) $T_{\mathrm{WQ}}=500^{\circ} \mathrm{C}$, and (d) $T_{\mathrm{WQ}}=440^{\circ} \mathrm{C}$.

Table 1 Thermal and mechanical properties of samples.

\begin{tabular}{|c|c|c|c|c|c|c|c|c|}
\hline Samples & $\begin{array}{l}\text { Diameter, } \\
(\mathrm{mm})\end{array}$ & $\begin{array}{c}\text { Thickness, } \\
\text { (mm) }\end{array}$ & Weight, mg & $\begin{array}{c}\text { Density, }(\rho) \\
\left(\mathrm{g} / \mathrm{cm}^{3}\right)\end{array}$ & $\begin{array}{l}\text { Thermal } \\
\text { diffusivity } \\
(\alpha), \mathrm{cm}^{2} / \mathrm{s}\end{array}$ & $\begin{array}{c}\text { Specific heat } \\
\text { capacity } \\
\left(C_{\mathrm{P}}\right), \mathrm{J} / \mathrm{gK}\end{array}$ & $\begin{array}{c}\text { Thermal } \\
\text { conductivity } \\
(\kappa), \mathrm{W} / \mathrm{mK}\end{array}$ & $\begin{array}{c}\text { Vickers } \\
\text { hardness, Hv }\end{array}$ \\
\hline AZ91D $+20 \% \mathrm{Gd}$ & 10 & 0.985 & 120.2 & 1.55 & 0.92 & 0.90 & 129.2 & 96.6 \\
\hline AZ91D & 10 & 0.995 & 128.8 & 1.65 & 0.30 & 0.91 & 45.1 & 63.7 \\
\hline
\end{tabular}

tangents. The second peak was located at $784^{\circ} \mathrm{C}$, which is assumed to be the $T_{\mathrm{L}}$ of AZ91D +20 mass $\% \mathrm{Gd}$. In Fig. 8(b), $T_{\text {cr }}=730^{\circ} \mathrm{C}$. Thus, undercooling for crystallization, $\Delta T_{\mathrm{cr}}=T_{\mathrm{L}}-T_{\mathrm{cr}}=54^{\circ} \mathrm{C}$, appeared in this measurement. The second and largest exothermic peak began at $636^{\circ} \mathrm{C}$. This peak converged with the base line at $463^{\circ} \mathrm{C}$, and no other peak was found below this temperature. Figure 9(a) shows that the first endothermic peak on heating appears at $428^{\circ} \mathrm{C}$, which corresponds to the decomposition of eutectic phase. In the figure, $T_{\mathrm{L}}$ was found to be $600^{\circ} \mathrm{C}$, which agreed well with the results of the preliminary measurement $\left(T_{\mathrm{L}}=599^{\circ} \mathrm{C}\right)$ and the value of $598^{\circ} \mathrm{C}$ reported in Ref. 2) within the measurement errors. Figure 9(b) shows that the first exothermic peak appears at $T_{\mathrm{cr}}=580^{\circ} \mathrm{C}$. Thus, $\Delta T_{\mathrm{cr}}=T_{\mathrm{L}}-T_{\mathrm{cr}}=20^{\circ} \mathrm{C}$. The peak ended at $479^{\circ} \mathrm{C}$, which was assumed to be the solidus temperature. The second and smaller peak is located at $430^{\circ} \mathrm{C}$, which corresponds to the eutectic reaction. The DTA behavior of AZ91D changed remarkably due to the addition of 20 mass $\% \mathrm{Gd}$, which is related to the microstructure in the next section.

The solidification behavior of AZ91 + 20 mass $\%$ Gd and AZ91D was examined by quenching experiments, and the results are shown in Figs. 10 and 11. In AZ91 + 20 mass $\%$ Gd, Figs. 10(a) $T_{\mathrm{WQ}}=700^{\circ} \mathrm{C}$ and 10 (b) $T_{\mathrm{WQ}}=650^{\circ} \mathrm{C}$ showed that the quenched microstructure contained dispersed $\mathrm{Al}_{2} \mathrm{Gd}$ particles in very fine dendrites, which are considered to have been the melt prior to quenching. This indicates that the exothermic peak at $730^{\circ} \mathrm{C}$ is induced by the crystallization of $\mathrm{Al}_{2} \mathrm{Gd}$, and primary phase is not $\alpha \mathrm{Mg}$ but $\mathrm{Al}_{2} \mathrm{Gd}$ in this alloy. In Fig. $10(\mathrm{c})$, for $T_{\mathrm{WQ}}=620^{\circ} \mathrm{C}$, large $\alpha \mathrm{Mg}$ dendrites appeared, causing the exothermic peak at $636^{\circ} \mathrm{C}$, as shown in Fig. $8(\mathrm{~b}) . \alpha \mathrm{Mg}$ grain growth continues until $T_{\mathrm{WQ}}=490^{\circ} \mathrm{C}$, as shown in Fig. $10(\mathrm{~d})$. At this temperature, however, a small amount of liquid remains at the grain boundary, as indicated by the arrow in the figure. Further cooling to room temperature yielded the microstructure, as shown in Fig. 3(a).

In Fig. $11(\mathrm{a})$, for $T_{\mathrm{WQ}}=600^{\circ} \mathrm{C}$, the quenched microstructure was that of the melt of AZ91D. In Fig. 11(b), for $T_{\mathrm{WQ}}=560^{\circ} \mathrm{C}$, an $\alpha \mathrm{Mg}$ dendrite was observed, showing that the exothermic peak starting at $T_{\mathrm{cr}}=580^{\circ} \mathrm{C}$ in Fig. 9(b) was caused by crystallization of the $\alpha \mathrm{Mg}$ dendrites. The $\alpha \mathrm{Mg}$ grains grow as the temperature decreases. As shown in Figs. $11(\mathrm{c})$, for $T_{\mathrm{WQ}}=550^{\circ} \mathrm{C}$, and $11(\mathrm{~d})$, for $T_{\mathrm{WQ}}=440^{\circ} \mathrm{C}$, the volume fraction of $\alpha \mathrm{Mg}$ grains increased as the grain shape became globular, and almost the entire volume was filled at this temperature. At the exothermic peak at $430^{\circ} \mathrm{C}$ shown in Fig. 9(b), eutectic reaction of $\alpha \mathrm{Mg}+\mathrm{Mg}_{17} \mathrm{Al}_{12}$ occurs, and the resulting microstructure forms, as shown in Fig. 3(b).

The thermal properties of these samples are shown in Table 1 . The density $(\rho)$, thermal diffusivity $(\alpha)$, specific heat capacity $\left(C_{\mathrm{p}}\right)$, and calculated thermal conductivity $(\kappa)$ are listed. The table shows that the densities of AZ91D +20 mass\% Gd and AZ91D were $1.55 \mathrm{~g} / \mathrm{cm}^{3}$ and $1.65 \mathrm{~g} / \mathrm{cm}^{3}$, respectively. These were small compared to the value in the literature for AZ91D of $1.81 \mathrm{~g} / \mathrm{cm}^{3} .^{2)}$ The values of $C_{\mathrm{p}}$ were $0.91 \mathrm{~J} / \mathrm{gK}$ for $\mathrm{AZ91}+20$ mass $\% \mathrm{Gd}$ and $0.90 \mathrm{~J} / \mathrm{gK}$ for AZ91D. These were also small compared to the value of $1.02 \mathrm{~J} / \mathrm{gK}$ reported in the literature. ${ }^{2)}$ This is attributed to the 


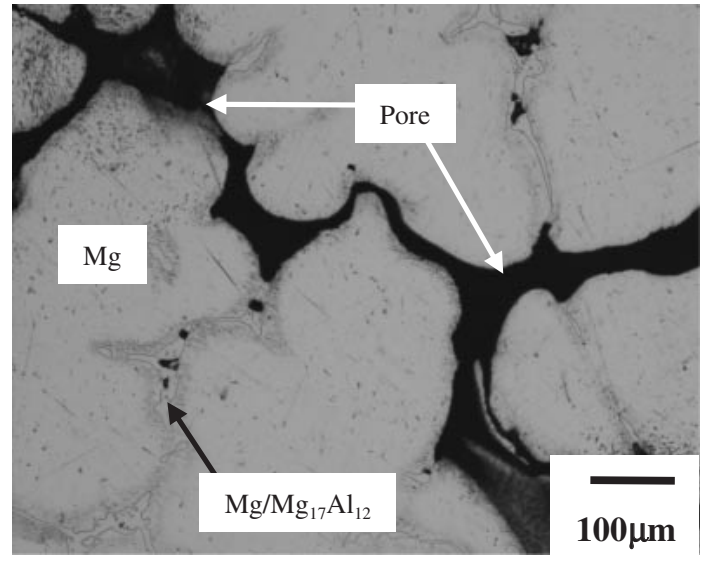

Fig. 12 Optical photomicrograph of solidification microstructure of AZ91D, showing pores at the grain boundary.

numerous pores in the microstructure. As shown in Fig. 12, a number of pores were observed in the solidified microstructure, particularly at the grain boundaries. Gas bubbles tended to remain in the liquid upon melting. That results from the process used to mix the AZ91D chips and the $10 \mathrm{~mm} \mathrm{Gd}$ blocks. The filling effect of the melt by its own weight was small, whereas the light weight of the sample, approximately $30 \mathrm{~g}$, caused pore formation. However, $\alpha$ and $\kappa$ increased remarkably by the addition of 20 mass $\% \mathrm{Gd}$, where $\kappa=$ $45.1 \mathrm{~W} / \mathrm{mK}$ for AZ91D and $\kappa=129.2 \mathrm{~W} / \mathrm{mK}$ for AZ91D + 20 mass $\% \mathrm{Gd}$. From the microstructure and SEM-EDS analyses, $\mathrm{Al}_{2} \mathrm{Gd}$ particles were revealed to consume $\mathrm{Al}$, thus reducing the $\mathrm{Al}$ content in $\alpha \mathrm{Mg}$ grains, as shown in Figs. 5 through 7 . Al significantly reduces the $\kappa$ of magnesium. ${ }^{4)}$ This is interpreted as being the result of lattice distortion of $\alpha \mathrm{Mg}$ crystals due to solid-solutioning, and, as a result, the mean free path of free electrons, which are heat carriers of solid metals, decreases. The reduction in $\mathrm{Al}$ content in the $\alpha \mathrm{Mg}$ grains should have substantially increased $\alpha$ and $\kappa$. The microstructure also showed that secondary phases, such as eutectic reaction products, were not observed at the grain boundary. This should have enhanced grain connectivity and heat conductance between $\alpha \mathrm{Mg}$ grains. The Vickers hardness is also listed in Table 1 , where $\mathrm{H}_{\mathrm{V}}=96.6$ for $\mathrm{AZ91}+$ 20 mass\% $\mathrm{Gd}$ and $\mathrm{H}_{\mathrm{V}}=63.7$ for AZ91D. As shown in Fig. 13, the Vickers hardness was measured as $\mathrm{H}_{\mathrm{V}}=$ 513-626 for three points on coarse $\mathrm{Al}_{2} \mathrm{Gd}$ particles that were locally residual in the microstructure. Based on these results, the number of hard $\mathrm{Al}_{2} \mathrm{Gd}$ particles dispersed in the microstructure was found to increase the mean hardness of the alloy.

\section{Summary}

In order to investigate the solidification microstructure and the material properties of AZ91D magnesium alloy and AZ91D with 20 mass\% Gd addition, these materials were prepared by use of the furnace cooling technique. From microstructure observation by optical microscopy and SEMEDS and from differential thermal analysis, quenching experiments, and measurements of the thermal properties and hardness, the following results were obtained.

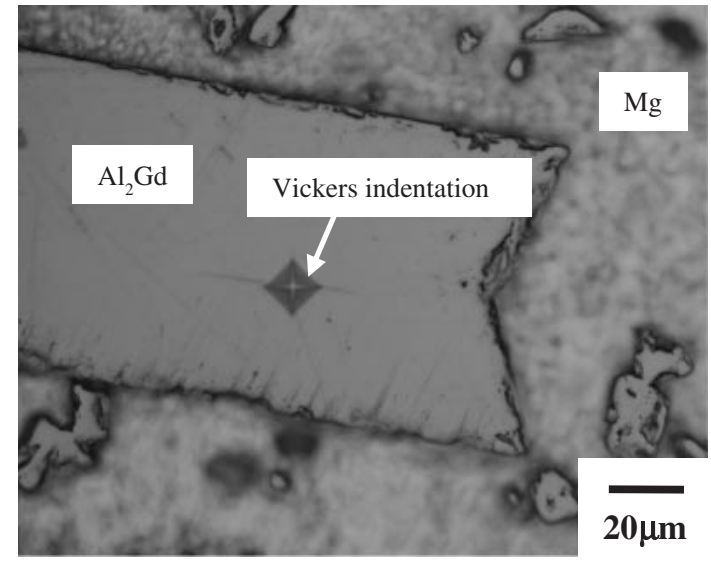

Fig. 13 Optical photomicrograph of micro-Vickers indentation on $\mathrm{Al}_{2} \mathrm{Gd}$ particle.

(1) In the microstructure of AZ91D +20 mass $\%$ Gd, globular $\mathrm{Al}_{2} \mathrm{Gd}$ particles were dispersed within the $\alpha \mathrm{Mg}$ matrix, and no grain boundary phases were observed. This differs from the microstructure of AZ91D, where eutectic $\alpha \mathrm{Mg}+\mathrm{Mg}_{17} \mathrm{Al}_{12}$ surround $\mathrm{Mg}$ grains in a web-like manner.

(2) SEM-EDS analyses revealed that the Al concentration in the $\alpha \mathrm{Mg}$ grains of AZ91D +20 mass\% Gd alloy decreased remarkably compared to that of AZ91D.

(3) Differential thermal analyses revealed that the melting temperature increased from 600 to $784^{\circ} \mathrm{C}$ by 20 mass $\%$ $\mathrm{Gd}$ addition, and the crystallization temperature increased from 580 to $730^{\circ} \mathrm{C}$.

(4) Quenching experiments were carried out in order to clarify the solidification behavior of AZ91D. In AZ91D + 20 mass\% Gd, the primary $\mathrm{Al}_{2} \mathrm{Gd}$ particles were found at $700^{\circ} \mathrm{C}$, and $\alpha \mathrm{Mg}$ equi-axed dendrites began to solidify at $636^{\circ} \mathrm{C}$. In AZ91D, the primary $\alpha \mathrm{Mg}$ began to solidify at $580^{\circ} \mathrm{C}$ and $\alpha \mathrm{Mg}+\mathrm{Mg}_{17} \mathrm{Al}_{12}$ eutectic precipitates from the remaining liquid at approximately $430^{\circ} \mathrm{C}$.

(5) Measurements of the material properties of these samples revealed that the thermal conductivity increased from $45.1 \mathrm{~W} / \mathrm{mK}$ to $129.2 \mathrm{~W} / \mathrm{mK}$ and the Vickers hardness $\mathrm{H}_{\mathrm{V}}$ increased from 63.7 to 96.6 by the addition of 20 mass $\% \mathrm{Gd}$. The increment of the thermal conductivity was explained by the decrease in the Al concentration in the $\alpha \mathrm{Mg}$ grains in the microstructure and the diminishment of the grain boundary phases, and the increment in hardness was explained by the dispersion of $\mathrm{Al}_{2} \mathrm{Gd}$ particles of high hardness.

\section{Acknowledgments}

The authors would like to thank Dr. Uchida at Tokyo Metropolitan Industrial Technology Research Institute for his XRD analyses.

\section{REFERENCES}

1) Japanese Industrial Standards H2222: Magnesium alloy ingots for die castings, (2003, Japanese Standards Association). 
2) Handbook of Advanced Magnesium Technology, ed. Y. Kojima, (Kallos publishing Co. 1td., 2000) pp. 155-233.

3) ASM Handbook vol. 3: Alloy Phase Diagrams, ed. H. Baker et al., (ASM international, 2.48).

4) Handbook of Advanced Magnesium Technology, ed. Y. Kojima, (Kallos publishing co. 1td., 2000) pp. 55-70.

5) Handbook of Advanced Magnesium Technology, ed. Y. Kojima, (Kallos publishing co. 1td., 2000) pp. 71-104.

6) A. K. Dahle, Y. C. Lee, M. D. Nave, P. L. Schaffer and D. H. St John: J. Light Met. 1 (2001) 61-72.

7) Y. Lu, Q. Wang, X. Zeng, W. Ding, C. Zhai and Y. Zhu: Mater. Sci. Eng. A 278 (2000) 66-76.

8) W. Qudong, L. Yizhen, Z. Xiaoqin, D. Wenjiang, Z. Yanping, L. Qinghua and L. Jie: Mater. Sci. Eng. A 271 (1999) 109-115.

9) ASM Handbook vol. 3: Alloy Phase Diagrams, ed. H. Baker et al., (ASM international, 2.220).

10) P. Vostry, B. Smola, I. Stulikova, F. von. Buch and B. L. Mordike: Phys. Status Solidi (a) 175 (1999) 491-500.

11) J. Cizek, I. Prochazka, B. Smola, I. Stulikova and V. Ocenasek: J.
Alloy. Compds. 430 (2007) 92-96.

12) M. Nishijima and K. Hiraga: Mater. Trans. 48 (2007) 10-15.

13) L. L. Rokhlin and N. I. Nikitina: Z. Metallkd. 85 (1994) 819-823.

14) S. Kamado, I. Iwasawa, K. Ohuchi, Y. Kojima and R. Ninomiya: J. Jpn. Inst. Light Metals 42 (1992) 727-733.

15) J. Grobner, D. Kevorkov and R. Schmid-Fetzer: Z. Metallkd. 92 (2001) 22-27.

16) G. Cacciamani, S. De Negri, A. Saccone and R. Ferro: Intermetallics 11 (2003) 1135-1151

17) ASM Handbook vol. 3: Alloy Phase Diagrams, ed. H. Baker et al., (ASM international, 2.45)

18) S. De Negri, A. Saccone, G. Cacciamani and R. Ferro: Intermetallics 11 (2003) 1125-1134.

19) L. L. Rokhlin, N. R. Bochvar and E. V. Lysova: J. Mater. Sci. Lett. 15 (1996) 2077-2079.

20) Japanese Industrial Standards R1611: Test methods of thermal diffusivity, specific heat capacity, and thermal conductivity for fine ceramics by laser flash method, (1997, Japanese Standards Association). 